\title{
La Iglesia que nace de la Pascua Seguimiento de Jesús y opción por los pobres
}

\author{
Xavier Alegre, \\ Centro de Reflexión Teológica, San Salvador, \\ Facultad de Teología de Cataluña, Barcelona.
}

\section{Introducción}

Quiero empezar recordando unas palabras que dijo monseñor Romero en su última homilía, comentando el Evangelio de Juan que acababa de leer:

Se nos advierte que de nada le sirve al hombre ganar todo el mundo si se pierde a sí mismo. No obstante, la espera de una tierra nueva no debe amortiguar, sino más bien avivar, la preocupación de perfeccionar esta tierra, donde crece el cuerpo de la nueva familia humana, el cual puede de alguna manera anticipar un vislumbre del siglo nuevo para esta tierra. Por ello, aunque hay que distinguir cuidadosamente progreso temporal y crecimiento del reino de Cristo, sin embargo, el progreso temporal, en cuanto puede contribuir a ordenar mejor la sociedad humana, interesa en gran medida al Reino de Dios. ${ }^{1}$

Estas palabras muestran la perfecta sintonía que unía a Mons. Romero con Jesús y con las Iglesias que nacieron de la Pascua. Y esta sintonía me parece importante porque estas Iglesias son, gracias al testimonio que nos ha quedado de ellas en los Evangelios, el punto de referencia fundamental, el criterio de discernimiento evangélico, para toda Iglesia cristiana. Y si algo aparece claramente en ellas es que son Iglesias que toman conciencia de que han de estar, como lo estuvo Jesús, al servicio del Reino de Dios ( $c f r$. Lc 8, 1).

De hecho, los Evangelios nos enseñan, sin lugar a dudas, que el Reino de Dios, tal como lo promovió Jesús, debe ser la tarea fundamental de toda Iglesia que se precie de ser fiel a Cristo ( $c f r$. Mt 4, 17; 10, 7).

1. Homilías. Monseñor Óscar A. Romero, vol. VI, San Salvador, 2009, p. 136. 
En los Evangelios, el Reino de Dios, que siempre es más grande, por ser de Dios y superar cualquier realidad humana, es don gratuito de Dios y tarea a la vez.

Por un lado, es don que hay que pedir ( $c f r$. Mt 6, 10) humildemente, conscientes de que, en un mundo profundamente marcado por la injusticia personal y estructural, lograr que Dios reine es algo que supera las fuerzas meramente humanas y pide, por tanto, conversión. Sólo Dios, para quien todo es posible ( $c f r$. Mc 10, 27), puede hacer que el Reino de Dios sea una realidad plena en un mundo dominado por la injusticia y en el que las inmensas mayorías empobrecidas son las grandes víctimas de la historia. Por eso, porque el Reino es ante todo don de Dios, monseñor Romero, siguiendo a Jesús ( $c f r$. Lc 5, 16; 6, 12; 11, 1-4), pasó largas horas de oración llenándose de Dios y buscando la fuerza para promover el Reino.

Pero, por otro lado, el Reino es también tarea que hay que realizar. Al fin y al cabo, esto es lo que hizo Jesús, que estaba convencido de que había que poner signos en este mundo de que Dios ya está reinando dinámicamente. Los milagros ( $c f r$ Lc 11, 20), y el hecho de que su actuación era una buena noticia para los pobres ( $c f r$. Mt 11, 2-6), son un testimonio de ello. Pues aunque el Reino de Dios "no es de este mundo" ( $c f r$. Jn 18, 36), es decir, no comparte la lógica de este mundo injusto, sin embargo, sí está en este mundo ${ }^{2}$. Y todo el que es de la verdad escucha la voz de Jesús y se deja configurar por la Verdad (cfr. Jn 18, 37), que es Jesús mismo (cfr. Jn 10, 6).

Ese doble aspecto lo entendió muy bien monseñor Romero, que supo unir la dimensión trascendente del Reino con la inmanente. Cuando decía en su última homilía que había que "distinguir cuidadosamente progreso temporal y crecimiento del reino de Cristo", aludía a la dimensión trascendente del Reino. Pero cuando añadía que "sin embargo, el progreso temporal, en cuanto puede contribuir a ordenar mejor la sociedad humana, interesa en gran medida al Reino de Dios", recordaba el aspecto inmanente del Reino de Dios, tal como lo predicó y encarnó Jesús. Por eso monseñor Romero supo, como Jesús, poner signos palpables para los empobrecidos y excluidos de este mundo de que el Reino de Dios ya se estaba haciendo presente prioritariamente para ellos, aunque no fuera aún una realidad plena y definitiva.

Es bueno, por tanto, que empecemos este congreso, en el que recordamos con cariño el testimonio martirial de monseñor Romero, recordando cómo fue la Iglesia que nació de la Pascua, una Iglesia a la que monseñor Romero quiso ser,

2. Cfr. X. Alegre, “Mi reino no es de este mundo' (Jn 18, 36). Conflictividad de la existencia cristiana en el mundo según el cuarto Evangelio", Estudios Eclesiásticos 54 (1979), pp. 499-525 (también en Íd., Memoria subversiva y esperanza para los pueblos crucificados, Madrid, 2003, pp. 309-333). 
y fue, siempre fiel. Fundamentalmente, fue una Iglesia totalmente impactada por la figura de Jesús de Nazaret, por su vida, su muerte y su resurrección. Por ello fue una Iglesia que se sintió llamada, ante todo, a seguir a Jesús y a optar por los pobres, tal como lo había hecho el Maestro.

Jesús había dado su vida, esperando, contra toda esperanza meramente humana, que Dios acabaría reinando en el mundo, pues con él Dios ya estaba actuando decisivamente en la tierra $(c f r$. Mc 1,15$)$. Y, a la vez, lo hizo con la certeza de que, como consecuencia de su actuación, un día Dios reinaría plenamente ( $c f r$. Mc 13, 24-27.28-37. También lo entendió así Pablo, según 1 Cor 15, 20-28). Sería realidad, entonces, el cielo nuevo y la tierra nueva en el que no habrá ya muerte, ni luto, ni llanto, ni dolor, porque todo lo viejo se habrá desvanecido ( $c f r$. Ap 21, 1-4).

Por ello, la Iglesia que nació de la Pascua fue una Iglesia que se distinguió por tres cosas: (1) recuperó la memoria de Jesús, que había puesto toda su vida al servicio del Reino de Dios; (2) puso a producir a la muerte de Jesús en la cruz, testimonio martirial del amor sin límites y gratuito del Hijo; y (3) dio testimonio de que Jesús seguía vivo, porque Dios había resucitado al Crucificado, dando la razón a la Víctima frente a sus victimarios. Tres aspectos que fueron también decisivos para la eclesiología que vivió y fomentó Mons. Romero.

\section{Recuperar la memoria de Jesús, que puso su vida al servicio del Reino de Dios}

Lo primero que hizo la Iglesia que nació de la Pascua fue proclamar la Resurrección del Crucificado como fundamento y garantía de la salvación (cfr. Rom 10, 9). Es el núcleo del kerigma (predicación) de la primera Iglesia. El mismo Pablo recuerda que él lo ha recibido de la tradición de la Iglesia que había nacido de la Pascua (cfr. 1 Cor 15, 1-5).

Pero por las tradiciones que recogieron los cuatro Evangelios podemos saber que, gracias a Pedro y a los demás discípulos y discípulas de Jesús, se recuperó también la palabra y la vida pública de Jesús, partiendo del hecho de que Jesús empezó a actuar por su cuenta, según Marcos, el Evangelio más antiguo, cuando vio que metían en la cárcel y asesinaban a su maestro Juan Bautista (cfr. Mc 1, 14-15) $)^{3}$.

Solo que ahora, después de la experiencia de la Pascua, la cruz y la Resurrección les abrieron los ojos de la fe a los discípulos para comprender en

3. También aquí podemos ver un paralelismo entre la vida de Jesús y la de monseñor Romero, pues fue precisamente el asesinato del P. Rutilio Grande lo que provocó un cambio radical en la actuación pastoral del arzobispo de San Salvador. 
profundidad lo que en vida de Jesús les había costado comprender ( $c f r$. Mc 8, 17-21.31-33).

Fue el don del Espíritu ( $c f r$. Hch 2) lo que les capacitó para entender, en primer lugar, la Escritura (cfr. Lc 24, 45-49), es decir, para comprender cómo el Antiguo Testamento iluminaba la dimensión más honda de Jesús en su relación con el Padre y en su relación con el mundo.

Y, a la vez, el Espíritu, además de recordarles con fidelidad lo que Jesús había hecho, les ayudó a actualizarlo ( $c f r$. Jn 14, 25-26; 16, 12-13), primero en Jerusalén $\mathrm{y}$, luego, en las Iglesias que fueron naciendo a lo largo del espacio y del tiempo (cfr. Jn 15, 26-27; Hch 1, 8). Por eso para Lucas, que ve a los Doce Apóstoles como los garantes de la fidelidad de la Iglesia a su Maestro, solo pueden formar parte de este círculo aquellas personas que han sido testigos de la vida pública de Jesús y de su resurrección, desde Juan Bautista hasta la Ascensión (cfr. Hch 1, 21-22).

La recuperación de la memoria de Jesús fue decisiva, por tanto, para la Iglesia que nació de la Pascua. Y lo siguió siendo cuando, al ir muriendo los primeros testigos, se corrió el peligro de tergiversar y manipular el mensaje de Jesús, tal como lo hicieron un poco más tarde los Evangelios apócrifos.

Por ello, la recuperación de esta fidelidad a la memoria de Jesús fue la gran aportación teológica del primero de los evangelistas hacia los años 70. Tal como nos muestra el Evangelio de Marcos, seguido luego por los otros evangelistas, la recuperación de la vida de Jesús es un criterio fundamental de discernimiento de la fe cristiana, pues no se puede comprender la muerte y la Resurrección de Jesús al margen de lo que fue su vida.

Para la primera Iglesia (iy para toda Iglesia, en principio!) no resultaba fácil entender, y mucho menos encarnar en la propia vida, el proyecto que Jesús había vivido. Él había sido un hombre extraordinario. Sin su apoyo en el día a día, resultaba difícil para los discípulos vivir lo que habían vivido con él. Verle morir en una cruz favorecía el desaliento. Pero los primeros compañeros y compañeras de Jesús lograron, gracias a la experiencia pascual y a la presencia del Espíritu en medio de la comunidad, encontrar la fuerza que necesitaban para continuar el proyecto de Jesús. Y se llenaron de esperanza.

\section{El impacto de la persona de Jesús}

A los primeros compañeros y compañeras de Jesús la persona de Jesús les había llegado al corazón. Su entrega generosa al servicio de los enfermos, pobres y marginados ( $c f r$. Mt 8-9), su valentía para denunciar la injusticia de los

4. Cfr. X. Alegre, El Evangelio de Judas. ¿Un "quinto" Evangelio auténtico?, San Salvador, 2006. 
poderosos, causante de los males de las mayorías empobrecidas ( $c f r$. Mc 10, 26; Mt 23, 1-12; Lc 13, 31-32), su palabra iluminadora, llena de vida eterna (cfr. Jn 6, 68; Mt 5, 3-10), fue algo que había marcado definitivamente su vida. No es entonces casual que, según los Hechos de los Apóstoles, Pedro resumiera así la vida de Jesús, en un discurso programático: "Pasó por el mundo haciendo el bien y curando a los oprimidos por el diablo" (Hch 10, 38). El diablo simboliza aquí todas las fuerzas del mal que se oponen al Reino de Dios y oprimen a los seres humanos. Frente a ellas, la actuación de Jesús había sido sanadora y liberadora (cfr. Mc 1, 21-28.32).

Por eso Lucas, el tercer evangelista, no duda en resumir así el proyecto de Dios que Jesús de Nazaret había venido a realizar en este mundo, mostrando que en él se habían cumplido ( $c f r$. Lc 4, 20) las promesas del Antiguo Testamento (cfr. Is 61, 1-2):

El Espíritu del Señor está sobre mí, porque me ha ungido para anunciar la buena noticia a los pobres, me ha enviado a proclamar la liberación a los cautivos y dar vista a los ciegos, a libertar a los oprimidos y a proclamar un año de gracia del Señor. (Lc 4, 18-19.)

Se trata, por tanto, de un proyecto liberador, en continuidad con el proyecto de Dios revelado en el Antiguo Testamento, que tiene como destinatarios privilegiados a los pobres. Pues, como muy bien expresó monseñor Romero, "la gloria de Dios es el pobre que vive". Por ello, solo si los empobrecidos de la tierra pueden vivir humana y dignamente, podemos pensar que Dios reina en la tierra.

Insisto en este aspecto porque eso, que es fundamental para comprender bien el proyecto de Jesús, lo entendió y lo vivió generosa y coherentemente monseñor Romero en su actuación pastoral al frente de la Iglesia de la arquidiócesis.

De hecho, Jesús fue un hombre bueno, entregado generosamente a los demás, revelando así el rostro misericordioso del Padre ( $c f r$. Lc 15, 11-32). Nunca marginó a nadie. Al contrario, puso su vida al servicio de los pobres y marginados, a los que consideró como el objeto privilegiado del amor de Dios, pues tenían la vida más amenazada. Los curaba (cfr. Mc 1, 40-45), los reconciliaba con Dios y con los demás ( $c f r$. Lc 7, 36-50), compartía la mesa con ellos (cfr. Mc 2, 15-17; Lc 15, 1-2), los invitaba a que le siguieran (cfr. Mc 1, 14), los amaba ( $c f r$. Lc 15). Apasionado, como lo estaba, porque Dios reinara en el mundo, puso toda su vida al servicio de este proyecto de liberación de los pobres y marginados social y religiosamente.

Se trataba de un proyecto que tenía sus raíces en el Antiguo Testamento. Pero precisamente porque su proyecto era el Reino de Dios, Jesús no sólo destacó por su bondad y su generosidad, sino que se señaló también por su talante profético 
que le llevó (y monseñor Romero lo aprendió de él) a denunciar la injusticia de los poderosos. Y la denominó "pecado".

Por ello le acusaron a Jesús de meterse en política ${ }^{6}$ y de poner en peligro al Imperio romano (de lo contrario, no hubiera muerto crucificado como un terrorista más).

Pero Jesús denunció la injusticia precisamente para ser fiel a la voluntad de Dios, tal como esta había sido expresada en el Antiguo Testamento. Se lo recuerda a Juan Bautista, cuando este quiere oponerse a que Jesús sea bautizado por él: "Deja eso ahora, pues conviene que cumplamos lo que Dios ha dispuesto" (Mt 3, 15; cfr. 5, 17-20).

De todos modos, la actuación de Jesús nos plantea una pregunta crucial: ¿por qué no solo los milagros de Jesús, reflejo de la misericordia del Padre, sino también la denuncia de la injusticia forman parte esencial de la Buena Noticia de Jesús, del Evangelio, tal como lo comprendió muy bien monseñor Romero?

5. Iluminado por Jesús, dijo monseñor Romero en el discurso que hizo con motivo del doctorado honoris causa que le dieron en Lovaina: "Pecado es aquello que dio muerte al Hijo de Dios, y pecado sigue siendo aquello que da muerte a los hijos de Dios. Esa fundamental verdad de la fe cristiana la vemos a diario en las situaciones de nuestro país. No se puede ofender a Dios sin ofender al hermano. Y la peor ofensa a Dios, el peor de los secularismos es, como ha dicho uno de nuestros teólogos: '... el convertir a los hijos de Dios, a los templos del Espíritu Santo, al Cuerpo histórico de Cristo en víctimas de la opresión y de la injusticia, en esclavos de apetencias económicas, en piltrafas de la represión política". Citaba al P. Ellacuría, ECA 353 (1978), p. 123.

6. Una acusación de la que también Mons. Romero tuvo que defenderse a menudo. Recordemos lo que dijo cuando le concedieron el doctorado en Lovaina: "La dimensión política de la fe no es otra cosa que la respuesta de la Iglesia a las exigencias del mundo real socio-político en que vive la Iglesia. Lo que hemos redescubierto es que esa exigencia es primaria para la fe y que la Iglesia no puede desentenderse de ella. No se trata de que la Iglesia se considere a sí misma como institución política que entra en competencia con otras instancias políticas, ni que posea unos mecanismos políticos propios; ni mucho menos se trata de que nuestra Iglesia desee un liderazgo político. Se trata de algo más profundo y evangélico; se trata de la verdadera opción por los pobres, de encarnarse en su mundo, de anunciarles una buena noticia, de darles una esperanza, de animarles a una praxis liberadora, de defender su causa y de participar en su destino. Esta opción de la Iglesia por los pobres es la que explica la dimensión política de su fe en sus raíces y rasgos más fundamentales. Porque ha optado por los pobres reales y no ficticios, porque ha optado por los realmente oprimidos y reprimidos, la Iglesia vive en el mundo de lo político y se realiza como Iglesia también a través de lo político. No puede ser de otra manera si es que, como Jesús, se dirige a los pobres". 
La razón está en la misión que había recibido de Dios. Jesús vino en nombre de Dios a anunciar que "el plazo se ha cumplido. El Reino de Dios está llegando. Conviértanse y crean en el Evangelio" (Mc 1, 15).

Pero ¿a qué se refería Jesús, sin explicarlo más concretamente, cuando anunciaba el Reino de Dios? La respuesta nos la aporta el Antiguo Testamento?

\section{El reinado de Dios en el Antiguo Testamento}

Según el Antiguo Testamento, Dios había escogido a un pueblo, Israel, para reinar en él y, a través de él, reinar en todos los pueblos de la tierra. Por eso, sólo Dios es el auténtico rey de Israel y, cuando Israel quiere tener un rey, Dios indica que no es a Samuel a quien el pueblo rechaza, sino a Dios mismo (cfr. 1 Sam 8, 6-9).

Pero el Dios que se revela en el Antiguo Testamento, y con el que Jesús está en íntima relación, hasta ser uno con Él ( $c f r$. Jn 10, 30; 14, 9-11), es un Dios compasivo y misericordioso, que escucha el clamor del pobre y del oprimido (Ex 3 ), se identifica con él, y pone en marcha un proyecto liberador que muestre que "otro mundo es posible".

Dios muestra que reina en el mundo precisamente en el hecho de que, siendo bueno y misericordioso con todas sus criaturas (Salmos 86, 15; 145, 9), transforma una realidad histórico-social injusta en otra justa, en la que reina la solidaridad y no hay pobres ( $c f r$. Dt 15,4$)$.

Pero para poder hacer realidad esa utopía, poniendo signos de ella ya en este mundo, Dios necesita un pueblo que viva de acuerdo con lo que pide la Alianza ( $c f r$. Ex 19,8) y así se convierta en un "reino sacerdotal", porque es el instrumento del "reinado de Dios" en el mundo ( $c f r$. Ex 19, 6; Ap 1, 6). La elección del pueblo de Dios, por tanto (y eso vale obviamente también para la Iglesia, que tiene su raíz en el pueblo de Israel, como subraya Pablo en Romanos 11), no es la consecuencia de los méritos del pueblo ( $c f r$. Dt 7, 6ss), ni un privilegio exclusivo, ya que Egipto y Asiria también son amados por Dios (cfr. Is 19, 19-25), sino un servicio a la liberación y salvación de todos los pueblos de la tierra (cfr. Gn 12, 1-3).

Por eso, Dios le pide a Israel que, dando gracias por la liberación gratuita que ha experimentado cuando era esclavo en Egipto ( $c f r$. Dt 26, 5-12), al llegar

7. Este aspecto lo desarrollo más en mi artículo "El Reino de Dios y las parábolas en Marcos", Revista Latinoamericana de Teología 23 (2006), pp. 3-30 (reproducido en mi libro La palabra no está encadenada, San Salvador, 2009, pp. 191-230).

8. Por eso, cuando un discípulo de Pablo proclama que Dios quiere salvar a todo el mundo (cfr. 1 Tim 2, 4), no podemos ignorar este trasfondo veterotestamentario si no queremos correr el peligro de espiritualizar indebidamente el proyecto salvador de Dios, tal como Jesús nos lo reveló. 
a la tierra prometida cumpla lo que Dios le pide en la Alianza (cfr. Ex 19, 5; Dt 26, 18-19).

Cumplir la Alianza implica que estructuren las leyes del pueblo de modo que no haya pobres en medio de ellos ( $c f r$. Dt 15,4 y todo el cap. 15), porque comparten (cfr. Dt 26, 13-14), perdonan las deudas cada 7 años, y cada 50 años vuelven a repartir la tierra para que todas las familias tengan una posibilidad de vivir humana y dignamente ( $c f r$. Lv 25).

Notemos aquí que, si Dios tiene tanto interés en que el pueblo guarde unas leyes que protejan al pobre y al emigrante ( $c f r$. Dt 26, 11-13), es porque Dios se caracteriza por ver el sufrimiento, oír el clamor del oprimido y acudir a liberarlo (cfr. Ex 3, 7-10; Ex 14-15; Sl 10, 17-18). Por eso el rey, si quiere ser un buen lugarteniente de Dios, debe defender al pobre ( $c f r$. Sl 72, 1-4.12-14), posibilitando así que Dios reine realmente.

Éste había sido el proyecto de Dios al escoger a Israel. Pero cuando Jesús apareció en Galilea, el pueblo de Dios no había conseguido cumplir con la tarea que Dios le había encomendado. No había dejado a Dios reinar, sino que había cambiado el Dios vivo por ídolos, como el poder y el dinero, que son la ruina de las mayorías empobrecidas de este mundo. Profetas tan significativos como Amós o Isaías no se habían cansado de denunciarlo (cfr. Is 1, 10-31; Am 5-6).

Jesús recoge la antorcha de estos profetas, como aparece claramente en el bautismo, donde toma conciencia de su vocación profética, marcada por la figura del Siervo de Yahvé ( $c f r$. Mc 1, 9-11 a la luz de Is 42, 1-2). Piensa que Dios le ha enviado a Israel para que, finalmente, el pueblo de Dios pueda dar el fruto de salvación universal que Dios espera de él ( $c f r$. Mc 12, 1-12). Es, pues, en este contexto, que Jesús quiso llamar a la conversión a este pueblo, anunciando la Buena Noticia de que Dios, con él, ya estaba reinando ( $c f r$. Mc 1, 14-15). Precisamente el hecho de que es Buena Noticia para los pobres y que ayuda a los enfermos y marginados es señal de que él es el Profeta esperado por Israel (cfr. Mt 11, 2-6). Este aspecto de Jesús, las Iglesias que nacieron de la Pascua lo comprendieron muy bien y lo encarnaron en sus vidas ( $c f r$. Mt 10, 7-8), convirtiéndose así en modelo de lo que luego fue la actuación de monseñor Romero.

A la vez, Jesús, como los profetas, no se cansó de denunciar la injusticia y las causas, hoy diríamos estructurales, que provocaban, ya en su tiempo, la marginación de las mayorías empobrecidas de su pueblo. Y lo hace, a veces, con palabras claras y duras que molestaron, como le ocurrió también a monseñor Romero, a las personas que él llamaba a la conversión:

¡Ay de ustedes, los ricos!, porque ya han recibido su consuelo. ¡Ay de ustedes, los que ahora están hartos!, porque tendrán hambre. ¡Ay de ustedes los que ahora ríen!, porque tendrán aflicción y llanto. ¡Ay cuando todos los hombres 
hablen bien de ustedes!, pues lo mismo hacían sus antepasados con los falsos profetas. (Lc 6, 24-26.)

A modo de conclusión de esta parte, quisiera añadir, por último, que hay otro aspecto de la actuación de Jesús en la que este fue profundamente fiel al Antiguo Testamento, un aspecto que también monseñor Romero supo encarnar en su actuación pastoral en la arquidiócesis de San Salvador. Me refiero a la unión indisoluble que hay para Jesús entre el amor a Dios y al prójimo ( $c f r$. Mc 12, 38-44 con Dt 6, 4-5 y Lv 19, 18).

Para Jesús es obvio que en el inicio de la vida cristiana se encuentra el amor gratuito de Dios, un amor que, como explica muy bien san Pablo, se revela claramente en el hecho de que, cuando éramos pecadores, Cristo murió por nosotros ( $c f r$. Rm 5, 5-10). Pero se trata de un amor que pide respuesta por nuestra parte. Por eso, para Jesús no respondemos al amor de Dios, no lo amamos realmente, si no amamos al prójimo como a nosotros mismos ( $c f r$. Mc 12, 28-34 par). Por eso es precisamente el amor al hermano, al prójimo, el que encarna la voluntad última de Jesús, su testamento (cfr. Jn 13, 34-35; 15, 11-17).

De hecho, para Jesús la regla de oro, el criterio decisivo para poder ver si cumplimos o no la voluntad de Dios, es el amor radical al prójimo: "Traten a los demás como quieran que ellos les traten a ustedes, porque en esto consisten la ley y los profetas" (Mt 7, 12). Por eso, consciente de la importancia de esta afirmación de Jesús, la Iglesia que nace de la Pascua insiste también en la unidad indisoluble del amor a Dios y al prójimo. Y en que el amar al prójimo como a uno mismo es la quintaesencia de la voluntad de Dios expresada ya en el Antiguo Testamento (cfr. Rom 13, 8-10).

De hecho, la Iglesia de Mateo fue aún más radical y concreta en esta identificación de cuál es realmente la voluntad de Dios para su Iglesia. Pues termina el último de los cinco grandes discursos de Jesús con una parábola que no tiene desperdicio, ni debe ser manipulada. Nos dice que, cuando comparezcamos ante Dios el día del juicio final, Jesús, el Hijo del hombre, nos preguntará ( $c f r$. Mt 25, 31-46) hasta qué punto hemos sido solidarios y hemos liberado de su sufrimiento a los pobres y marginados. Más aún, nos dirá que él se ha identificado plenamente con los que consideramos a veces los más pequeños, con los que padecen hambre y sed, sufren desnudez y están enfermos o en la cárcel. Y subraya que Dios nos juzgará por nuestro comportamiento frente a ellos, y no por determinados actos cúlticos, por más solemnes que hayan sido.

Este último aspecto, que fue fundamental para la Iglesia de Mateo, monseñor Romero supo encarnarlo bien en su actuación pastoral al servicio prioritario de los pobres y excluidos por un sistema económico, político, y a veces religioso, injusto, que provocaba, como ya ocurría en el tiempo de Jesús, el sufrimiento y la muerte de las mayorías empobrecidas de su arquidiócesis y de su país. 
Y, a la vez, monseñor Romero', como Jesús, y este aspecto lo ha subrayado sobre todo la Iglesia de Lucas ( $c f r$. Lc 16, 13), no se cansó de interpelar a los ricos y a los causantes del sufrimiento injusto de las mayorías populares, para que se convirtieran, como Zaqueo (cfr. Lc 19, 1-8). Y para que se abrieran a la Buena Noticia del Reino de dos maneras: compartiendo sus bienes con los necesitados y transformando unas estructuras económicas y políticas, que eran las causantes de tanto sufrimiento innecesario. Para Jesús es evidente que no se puede servir al mismo tiempo a Dios y al Dinero ( $c f r$. Lc 16, 13). Con ello, Jesús está haciendo alusión a un pecado que hoy llamamos "estructural", y que puede afectar a todo el mundo, porque tiene sus raíces en el pecado personal que no nos deja ver, ni tratar, a todas las demás personas como hermanos y hermanas.

\section{Continuidad entre Israel y la Iglesia}

Es, entonces, en este contexto del Reino de Dios donde aparece la continuidad entre Israel y la Iglesia que nace de la Pascua (cfr. Romanos 11).

Llama la atención que Jesús, de entrada, no intentó fundar una Iglesia. Es algo obvio. La Iglesia, el pueblo de Dios, ya existía. Él había venido más bien a cumplir las promesas hechas por Dios a su pueblo en el Antiguo Testamento y, por tanto, a reunir las ovejas perdidas de la casa de Israel (cfr. Mt 9, 36-38), tal como había prometido Dios a través del profeta Ezequiel (cfr. Ez 34). Jesús sabía que Dios había escogido a Israel, por pura gracia ( $c f r$. Dt 7, 6ss), para que se convirtiera en una luz y en una bendición para todos los pueblos de la tierra ( $c f r$. Gn 12, 1-3). Y que debía serlo por su estilo de vida, alternativo a los falsos valores de este mundo, mostrando, con su modo de vivir, que "otro mundo es posible", un mundo en el que no hubiera pobres porque hasta las leyes del pueblo los protegían. Y porque todos comparten lo que tienen con los más pobres (cfr. Dt 26, 11ss), a fin de poder erradicar la pobreza de este mundo, donde los empobrecidos son mayoría.

Todo el sermón de la montaña ( $c f r$. Mt 5-7) quiere ser una radicalización de estos valores que resultan alternativos, contraculturales, para un mundo egoísta.

9. Recojo aquí sólo un texto significativo: "Un llamamiento a la oligarquía. Les repito lo que dije la otra vez: No me consideren juez ni enemigo. Soy simplemente el pastor, el hermano, el amigo de este pueblo, que sabe de sus sufrimientos, de sus hambres, de sus angustias; y, en nombre de esas voces, yo levanto mi voz para decir: no idolatren sus riquezas, no las salven de manera que dejen morir de hambre a los demás, compartir para ser felices.

El cardenal Lorscheider me dijo una comparación muy pintoresca: 'Hay que saber quitarse los anillos para que no le quiten los dedos'. Creo que es una expresión bien inteligible. El que no quiere soltar los anillos se expone a que le corten la mano; y el que no quiere dar por amor y por justicia social se impone a que se lo arrebaten por violencia" (Homilía del 6 de enero de 1980). 
Pero son estos valores precisamente los que la Iglesia, como pueblo de Dios, está llamada a encarnar para poder ser así sal de la tierra y luz del mundo ( $c f r$. Mt 5, 13-16).

No es casual, entonces, en este contexto, que, sorprendentemente para la lógica de este mundo (una lógica a la que Israel desgraciadamente demasiado a menudo había sucumbido, ¡lo cual es una advertencia para la Iglesia!), Jesús no quisiera realizar el proyecto liberador desde el poder, sino desde el servicio, simbolizado por la figura misteriosa del Siervo de Yahvé, que carga con las consecuencias del pecado y así nos libera (cfr. Mt 8, 16-17; 12, 15-21).

Sin embargo, Jesús actúa con una autoridad, diríamos "moral"10, que sorprende a sus mismos compañeros y compañeras, porque supera con creces la autoridad de los escribas y fariseos ( $c f r$. Mc 1, 22.27; Mt 7, 28-29). Era una autoridad que brotaba de su unión íntima con Dios, al que llamaba familiarmente Abbá, "papá querido". Y con el que entraba, como hará luego también monseñor Romero, en relación profunda en largas horas de oración ( $c f r$. Mc 1, 35; Lc 5, 16; $11,1-4 ; 22,39-46$, etc.).

Desgraciadamente, el anuncio de la venida del Reino de Dios, tal como Jesús lo encarnaba, provocó la división entre la gente (cfr. Lc 2, 34-35). Por un lado, provocó el entusiasmo entre el pueblo (sobre todo en los inicios: $c f r$. Mc 1, $28.37 .45 ; 2,2 ; 3,7.20 ; 4,1 ; 6,31-34)$. Y fue así porque "pasó haciendo el bien y sanando a los oprimidos por el diablo" (Hch 10, 38; cfr. Mt 8-9).

Pero pronto provocó también oposición entre sus adversarios ( $c f r$. Mc 3, 6), una oposición que cada vez fue creciendo más, como le ocurrió a monseñor Romero. Pero a medida que creció la oposición, Jesús fue radicalizando su predicación (cfr. Mc 8, 31-10, 45) para evitar malentendidos (cfr. Mc 8, 27-30). Y él mismo se marginó con los marginados ( $c f r$. Lc 9, 57-58) para acabar muriendo en una cruz, como un marginado más de este mundo.

\section{Poner a producir su martirio, su muerte en la cruz, testimonio máximo de amor}

La muerte de Jesús en la cruz, por amor a la humanidad y al Padre, es el fundamento del amor cristiano. Y la expresión máxima del amor de Dios a la humanidad ( $c f r$. Jn 3, 16). De hecho, nadie ama más que el que da la vida por los demás ( $c f r$. Jn 15, 13).

Pero, ¿por qué tuvo que morir Jesús? ¿Cómo pudieron acusarle de blasfemo y terrorista? ¿Por qué son calumniados y tienen que morir, al igual que Jesús, profetas y pastores tan maravillosos como monseñor Romero?

10. ¡También monseñor Romero tuvo una autoridad moral indiscutible! 
Cuando la Iglesia que nace de la Pascua se pregunta por qué Jesús, que fue un hombre lleno de bondad y de compasión, un hombre que transparentaba la misericordia del Padre ( $c f r$. Lucas 15), tuvo que morir en una cruz, llega a la conclusión de que fue la injusticia personal y estructural que domina nuestro mundo la que quiso acabar con Jesús. En eso coinciden todos los Evangelios. Como dice muy bien J. I. González Faus, Jesús tuvo que morir "porque los hombres matamos". Y Jesús quería poner punto final a esta espiral de violencia que tanto sufrimiento innecesario provoca en el mundo.

Pero fue también el amor fiel de Jesús al proyecto del reinado de Dios lo que hizo que Jesús estuviera dispuesto a morir en una cruz, antes que abandonar el proyecto liberador que el Padre le había confiado. Y en eso, monseñor Romero también le siguió.

Jesús no buscó, de entrada, la confrontación. Pues, como acabamos de ver, quería reunir, por encargo del Padre, las ovejas perdidas de la casa de Israel ( $c f r$. Mc 6, 34) y reconstituir el pueblo de Dios, tal como Dios había prometido en el Antiguo Testamento (cfr. Ez 34; Lc 15, 3-7). Pero el modo como hacía presente el Reino de Dios se fue volviendo cada vez más conflictivo ( $c f r$. Mc 2, 1-3, 6; 6, 1-6a), escandaloso para los que no se querían convertir a la Buena Noticia del Reino de Dios, y difícil de entender y de vivir para los que querían seguirlo ( $c f r$. Mc 8, 32-33; 9, 32ss; 10, 42-45). Pues la lógica de Jesús, que es una lógica configurada por el amor gratuito de Dios (cfr. Rom 5, 6-11.20b), no era evidentemente la lógica de este mundo, como le recuerda Jesús a Pedro, cuando este se opone a que Jesús pueda morir en una cruz ( $c f r$. Mc 8, 21-33; $c f r$ también Mt 20, 1-16; 25, 31-46; Lc 14, 15-24).

Es muy significativo que cuando Marcos quiso indicar por qué Jesús encontró una oposición tan radical hasta el punto de que quisieran asesinarlo, da una respuesta muy sencilla: porque puso el bien del ser humano como criterio decisivo para cumplir la voluntad de Dios.

El amor al prójimo en necesidad expresa algo tan fundamental y sagrado que puede pasar incluso por encima de leyes tan importantes para Israel como la ley de Dios que mandaba guardar el sábado ( $c f r$. Ex 20, 8-11). Pues, si en Mc 3, 6 los partidarios de una religiosidad tan popular y comprometida, como la de los fariseos, y los políticos, partidarios del rey Herodes, deciden matar a Jesús, ello se debe a que ha curado en sábado a un hombre que tenía la mano paralizada ( $c f r$. Mc 3, 1-5). Y una religión que prioriza el bien del pobre y del necesitado, por lo visto, no les interesa, más aún, les resulta peligrosa para sus propios intereses.

Por otro lado, y como acabamos de ver en el Evangelio de Mateo, lo que Dios espera de cualquiera de las personas que formamos su Iglesia, es que seamos solidarios de todas las personas marginadas, empobrecidas y que padecen necesidad. Según Jesús, ellas son el gran sacramento que nos pone en contacto 
con él, identificado precisamente con ellas y no con los sacerdotes del Templo de Jerusalén o con las personas poderosas y socialmente significativas en el pueblo de Dios ( $c f r$. Mt 25, 31-46). Por eso, la opción por los pobres, que tan bien supieron explicitar Medellín, Puebla y Aparecida, está en el corazón mismo de la revelación del Nuevo Testamento. Y de toda Iglesia que quiera ser fiel seguidora de Jesús.

De hecho, fue Marcos el primer evangelista que puso por escrito esa toma de conciencia de que era precisamente el modo de vida que Jesús había llevado, y la predicación concreta que había hecho, lo que había provocado que tuviera que morir en una cruz, condenado por las autoridades políticas, económicas y religiosas de su mundo.

Y eso le pareció a Marcos tan fundamental, que estructura todo su Evangelio de modo que la sombra de la cruz penda sobre toda la obra ${ }^{11}$. Pues a medida que va quedando cada vez más claro que el modo como Dios va a reinar no es creando un reino poderoso, alternativo al de los romanos, sino liberando al pobre y al oprimido, la oposición va creciendo.

En eso, la vida de monseñor Romero se pareció a la de Jesús. Lo formuló muy agudamente, con su clarividencia habitual, Ignacio Ellacuría en 1985, cuando la UCA le concedió a Romero el doctorado honoris causa:

En una sociedad configurada por los poderes de la muerte, él [monseñor Romero], que era promotor de los principios de la vida, no pudo ser tolerado. Como la de su gran maestro Jesús de Nazaret, su misión pública al frente del arzobispado sólo duró tres años. Reunidos los poderes de las tinieblas, decidieron acabar con quien, como en el caso de Jesús, fue acusado de andar soliviantando a la gente desde Galilea hasta Judea, desde Chalatenango hasta Morazán. Y lo acallaron de un tiro mortal porque el pueblo no hubiera permitido que lo crucificaran en público. Sólo así pudieron acallar al profeta. Pero ya para entonces la semilla había fructificado y su voz había sido recogida por miles de gargantas que con Monseñor habían recobrado su voz perdida. Los sin voz ya tenían voz, la suya y la de Monseñor. Y al quedar huérfanos, podían alcanzar su mayoría de edad y convertirse así [Monseñor] en padre de nuevos hijos, innumerables como las arenas del mar. Y es que el asesinado era un mártir. Lo mataron porque iluminaba y denunciaba desde el Evangelio los males del país y a quienes los perpetraban, pero murió porque el amor de Dios y el amor del pueblo le estaban pidiendo dar su vida en testimonio de lo que creía y de lo que practicaba. Por eso resucitó en el pueblo por el que había

11. $C f r$. X. Alegre, "Marcos o la corrección de una ideología triunfalista. Pautas para la lectura de un Evangelio beligerante y comprometido", Revista Latinoamericana de Teología 2 (1985), pp. 234 y ss. (también en Íd., Memoria subversiva, óp. cit., pp. 96 y ss.). 
muerto, y por eso esperó también la resurrección cristiana en la que confiaba sin asomo de duda.

Ante la realidad de la muerte y Resurrección de Jesús, la Iglesia que nace de la Pascua toma conciencia de que la manera como puede poner a producir todo el amor que ha quedado testimoniado en la cruz de Jesús es prosiguiendo el proyecto por el que él había dado la vida. Por eso no es casual que, para explicar lo que significó para sus discípulos la experiencia pascual, todos los evangelistas contaran, desde la luz de la Pascua, lo que había sido la vida de Jesús, que le llevó a la cruz y a la Resurrección. Y es muy significativo que fuera precisamente el primer evangelista (seguido, luego, por los demás evangelistas) el que quiso recuperar toda la vida de Jesús situándola en el marco de un llamamiento a seguir a Jesús (cfr. Mc 1, 16-20 con 16, 7). Un seguimiento que implicaba, como en Jesús, la opción por los pobres.

De todos modos, llama la atención, ante la creciente oposición que va encontrando Jesús, que el Maestro no se desalentara, ni abandonara o edulcorara el proyecto que Dios le había confiado. Ante la creciente oposición, incluso por parte de los (sumos) sacerdotes del pueblo de Dios, Jesús no renuncia a anunciar el Reino, porque piensa que el esfuerzo merece la pena, ya que el Reino de Dios es como un tesoro, una perla preciosa, por el que vale la pena renunciar a todo lo demás (cfr. Mt 13, 44-46).

Y, por otro lado, no se deja desalentar por los fracasos aparentes que acompañan su actuación y que le llevan a tomar conciencia de que acabarán asesinándolo. Pues desde su honda relación con Dios, y en eso fue seguido por monseñor Romero, piensa que hay motivos para tener esperanza, aunque el éxito superficial no acompañaba su actividad (cfr. Mc 4, 3-9.30-32), como después tampoco acompañará la de las Iglesias que vayan naciendo de la Pascua. Estas Iglesias serán también perseguidas ( $c f r$. Mc 13, 9-13; Mt 10, 16-33; Lc 21, 12-19), como lo había sido su Maestro ( $c f r$. Jn 15, 18-21). De hecho, Jesús siguió, a pesar de la creciente oposición y de las amenazas de muerte, fiel a su proyecto (y en esto fue seguido también por monseñor Romero), porque estaba convencido de que el Reino es algo que está en manos de Dios y tiene una fuerza imparable, como la semilla que crece por sí sola ( $c f r$. Mc 4, 26-29).

Pero mantener firme la esperanza en medio de los fracasos aparentes y de la oposición creciente no resultaba nada fácil. Como tampoco resulta fácil seguir a Jesús en su opción preferente por los pobres y en la denuncia de la injusticia. Por esto las Iglesias que nacen de la Pascua insisten, basándose en la enseñanza de Jesús, en que para poder vivir trabajando por el Reino hay que convertirse 
continuamente y perseverar en la oración, como muy bien lo comprendió más tarde monseñor Romero ${ }^{12}$.

Jesús, en todo caso, no se arrugó ante las amenazas de muerte. Más aún, confió en que su entrega generosa por el proyecto del Reinado de Dios sería semilla fecunda que haría que el Reino pudiera desarrollarse plenamente ( $c f r$. Jn 12, 24). Y aunque fue muy lúcido y anunció que acabarían matándolo (cfr. Mc 9, 31; 12, 6-8), anunció también que la muerte no sería la última palabra de Dios sobre él, sino que Dios le resucitaría personalmente, de modo que, como recuerdan los Evangelios, acabaría convirtiéndose en la piedra angular sobre la que se edificaría la Iglesia que nacería de la Pascua ( $c f r$. Mc 12, 10-11). Por eso entregó su vida libre y generosamente ( $c f r$. Jn 10, 17-18).

Esa generosidad frente a la propia muerte y la confianza de que ésta no sería inútil, sino que serviría para la realización del proyecto salvador de Dios, es la que inspiró sin duda a monseñor Romero cuando, al prever que lo iban a matar, expresó su fe en Dios, que resucita a los muertos, y confió en que resucitaría en el pueblo salvadoreño:

He sido frecuentemente amenazado de muerte. Debo decirle que como cristiano no creo en la muerte sin resurrección; si me matan, resucitaré en el pueblo salvadoreño. Se lo digo sin ninguna jactancia, con la más grande humildad: como pastor estoy obligado por mandato divino a dar la vida por quienes amo, que son todos los salvadoreños; aun por aquellos que vayan a asesinarme. Si llegaran a cumplirse las amenazas, desde ya ofrezco a Dios mi sangre por la redención y resurrección de El Salvador.

El martirio es una gracia que no creo merecer, pero si Dios acepta el sacrificio de mi vida, que mi sangre sea semilla de libertad y la señal de que la esperanza será pronto una realidad. Mi muerte, si es aceptada por Dios, sea por la liberación de mi pueblo y como un testimonio de esperanza en el futuro. Puede decir usted, si llegasen a matarme, que perdono y bendigo a quienes lo hagan; ojalá sí se convenzan de que perderán su tiempo. Un obispo morirá, pero la Iglesia de Dios, que es el pueblo, no perecerá jamás.

12. Monseñor Romero dijo en su homilía el 13 de noviembre de 1977: "Yo, que les estoy hablando, necesito convertirme continuamente. El pecador, el religioso, la religiosa, el colegio católico, la parroquia, el párroco, la comunidad, la Iglesia, pues, tiene que convertirse a lo que Dios quiere en este momento de la historia de El Salvador. Si uno vive en un cristianismo que es muy bueno, pero no encaja con nuestro tiempo, que no denuncia las injusticias, que no proclama el Reino de Dios con valentía, que no rechaza el pecado de los hombres, que consiente, por estar bien con ciertas clases, los pecados de esas clases, no está cumpliendo su deber, está pecando, está traicionando su misión". 


\section{Dar testimonio de que Dios resucitó a Jesús, el Crucificado, dando la razón a la Víctima frente a los victimarios}

La Resurrección de Jesús es el fundamento de la esperanza cristiana ( $c f r$. 1 Cor 15, 13-14). De hecho, el aparente fracaso de Jesús muriendo en una cruz podía llevar a pensar que Dios no estaba con él. Y que su vida, por tanto, no merecía la pena. Jesús habría sido, al menos para sus amigos, tan sólo una más de las numerosas personas buenas e idealistas en la historia, que han acabado víctimas de los poderes constituidos de este mundo, que tan a menudo se dejan dominar por el egoísmo ( $c f r$. Mc 10, 42).

Pero la experiencia de la Resurrección cambió radicalmente la visión de la muerte de Jesús. En la conciencia de los amigos y amigas de Jesús, profundamente marcados por la religión judía, la Resurrección implicaba que Dios había tomado partido a favor de Jesús. Y si Dios había dado la razón a la Víctima frente a los victimarios, ello significaba que valía la pena vivir como Jesús vivió. Y que, al final, el bien, que Jesús había encarnado en su vida, triunfaría sobre el mal.

Reflexionando sobre el significado de la Resurrección de Jesús, Jon Sobrino saca una consecuencia importante:

Dios ha resucitado a quien, por haber vivido de una determinada manera, había sido crucificado. En una palabra, Dios ha resucitado a un justo e inocente y, por ello, a una víctima. La Resurrección de Jesús, pues, no es sólo símbolo de la omnipotencia absoluta de Dios — como si Dios hubiese decidido arbitrariamente, sin conexión con la vida y el destino de Jesús, mostrar su omnipotencia y revelarse así como Dios-, sino que es presentada como la defensa que hace Dios de la vida del justo y de las víctimas.

Por eso se puede afirmar que la Resurrección de Jesús es una Buena Noticia para las víctimas. Y la garantía de que Dios les hará justicia. A la vez que una invitación a vivir tal como Jesús había vivido en su vida pública.

Fijémonos en que esta experiencia fundamental posibilitó el nacimiento de la Iglesia después de la Pascua. Los discípulos tomaron conciencia del gran privilegio que habían tenido al poder ser testigos de la vida de Jesús, de su modo de hablar de Dios y de su acción liberadora, generosa hasta dar la vida por ello. Era un don que se les convertía a ellos ahora en tarea. Había que dar testimonio de algo que cambiaba radicalmente el modo de ver la realidad. Y que era una Buena Noticia para el mundo entero. Y, a la vez, daba una luz nueva a la manera como el Dios de Israel se había hecho presente una vez más y había actuado en este mundo, tan necesitado de salvación.

Ahora lo fundamental para sus discípulos no era llorar su muerte. Ni buscar entre los muertos al que les había salido al encuentro y se les había revelado como vivo (cfr. Mc 16, 1-8; Mt 28, 1-8; Lc 24, 1-8; Jn 20, 1-18). Lo fundamental 
era recuperar el proyecto de Jesús y procurar vivirlo, tal como él lo había enseñado y vivido, hasta dar su vida por ello en una cruz. Y había que hacerlo siguiendo a Jesús y haciendo, como él lo había hecho, una opción por los pobres. Aunque ello pudiera llevar — como de hecho llevó- a los discípulos a ser perseguidos. Ya se los había advertido el Maestro, preparándolos para lo que les ocurriría después de Pascua:

Les he dicho esto para que su fe no sucumba en la prueba. Porque les expulsarán de la sinagoga. Más aún, llegará un momento en el que les quitarán la vida pensando que dan culto a Dios. Y actuarán así porque no conocen al Padre ni me conocen a mí. Se los digo de antemano para que, cuando llegue la hora, recuerden que ya se los había anunciado yo. (Jn 16, 1-4.)

Por eso en el corazón de la vida de la Iglesia que nace de la Pascua resuena sin cesar la palabra de Jesús: "Si alguno quiere venir detrás de mí, que renuncie a sí mismo, que cargue con su cruz y que me siga" (Mc 8, 34). Pues a la luz del Crucificado, a quien Dios ha resucitado, "una vida crucificada y entregada al servicio y en defensa de los crucificados es la mejor expresión de fe viva en el Resucitado"13.

La experiencia pascual llevó a la Iglesia, como muy bien formula Mateo ( $c f r$. 28, 16-10), por un lado, a participar plenamente de la vida de Jesús, gracias al bautismo, que expresa el don del amor gratuito de Dios, que lleva a la comunión con Él. Pero, por otro, implicó también la misión de convertir a todo el mundo en discípulo de Jesús, enseñándole a guardar todo lo que Jesús había enseñado en su vida terrena ${ }^{14}$.

Pero no se trataba de reproducir las palabras de Jesús como si fueran un fósil. Por la Resurrección de Jesús, la Iglesia sabía que Jesús seguía vivo. Por ello, la

13. J. A. Pagola, Creer en el Resucitado. Esperar en nuestra resurrección, Santander, 1991, p. 17. En la misma línea, J. Sobrino ("La Pascua de Jesús y la revelación de Dios desde la perspectiva de las víctimas”, Sal Terrae 83 [1995], p. 205) saca la siguiente conclusión: "Por decirlo desde el principio, el misterio pascual revela: (1) a un Dios parcial hacia las víctimas, a las que hace justicia; (2) a un Dios en lucha con los dioses, 'perdedor' y 'vencedor', digamos, a lo largo de la historia; (3) a un Dios que es, a la vez, mayor y menor, dialéctico por lo tanto; y, por ello, (4) a un Dios que sólo al final será todo en todo, y de ahí su futuridad. Correlativamente, la fe —en el sentido de fides qua - en ese Dios significa: (1) esperanza en que el verdugo no triunfará sobre la víctima; (2) praxis agonista contra los ídolos; (3) dejar a Dios ser Dios, misterio absoluto; y (4) caminar humildemente en la historia hasta su consumación".

14. Al indicar que el Resucitado se aparece en una montaña de Galilea, Mateo está pensando, de modo especial, en el Sermón de la Montaña, al inicio del Evangelio, que es como la carta magna de la Iglesia de Mateo ( $c f r$. Mt 5-7). 
fidelidad a Jesús debía ser creadora $^{15}$, encarnando el proyecto de Jesús en cada Iglesia, teniendo en cuenta los signos de los tiempos, es decir, la realidad que vivía cada Iglesia. Para ello tenían la ayuda del Espíritu, quien, además, les posibilitaba la unión íntima con el Resucitado, a semejanza de la manera como la vid está unida al sarmiento, pues solo si la Iglesia se mantenía unida a Jesús, podía dar fruto abundante, aunque encontrara oposición y no tuviera éxito aparente ( $c f r$. Jn 15, 1-10).

\section{Conclusión}

¿Cómo fueron, pues, las Iglesias que nacieron de la Pascua? Fueron Iglesias que, recuperando la memoria de lo que Jesús había dicho y hecho, se sintieron llamadas, por don gratuito de Dios, a ser pueblo de Dios, realizando la Nueva Alianza (cfr. Mc 14, 22-25; 1 Cor 11, 23-25; cfr. Jer 31, 31-34; Ez 36, 24-27) ${ }^{16}$. Por eso, cuando Lucas nos quiere presentar el modelo de Iglesia a inicios del cristianismo, nos describe la primera, la Iglesia madre de Jerusalén, como una Iglesia en la que no hay pobres, porque todos comparten ( $c f r$. Hch 2, 42-47; 4, 32-35).

Así se cumple lo que Dios había encargado a Israel a través de Moisés ( $c f r$. Dt $15,4)$. Y señala que el "pecado original", que introdujo la muerte en esta comunidad, fue el de Ananías y Safira, quienes mintieron a los Apóstoles para no tener que compartir todo lo que tenían con los demás ( $c f r$. Hch 5, 1-11).

Por otro lado, fueron Iglesias que pusieron a producir la muerte de Jesús, recordando fielmente lo que este había hecho y dicho a lo largo de una vida vivida totalmente para los demás, sobre todo a favor de los más pobres y marginados. Por ello, después de Pascua y por fidelidad a Jesús, desde la conciencia de que Dios había dado la razón al Crucificado, se sintieron llamados a seguir a Jesús y a optar por los pobres, como lo había hecho el Maestro. Fueron Iglesias que se distinguieron radicalmente por su servicio al mundo y a los pobres ( $c f r$. Mc 10, 42-45; Jn 13, 1-20), respetando, por obediencia a Jesús, la fraternidad radical de todos los miembros de la Iglesia (cfr. Mt 23, 1-12) ${ }^{17}$.

15. La Iglesia de Juan testimonia muy bien este aspecto.

16. Cfr. X. Alegre, "Utopía: La Iglesia tal como Jesús la quería”, en Íd., Iglesia, ¿de dónde vienes?, ¿a dónde vas?, Barcelona, 1989, pp. 19-52 (también en Íd., Memoria subversiva, óp. cit., pp. 171-200).

17. Quisiera recordar sólo dos textos de Mons. Romero que muestran su afinidad con la Iglesia servicial y fraternal que quería Jesús, según los Evangelios: "Así, como hermano, como amigo, es como quiero ser considerado en mi ministerio, es como yo he hablado en esta carta, para alegrarme precisamente de que Dios me ha preparado un pórtico inesperado para entrar en mi nuevo ministerio jerárquico" (17 de abril de 1977). "Los obispos no mandamos con un sentido despótico. No debe ser así. El obispo es el más humilde servidor de la comunidad, porque Cristo lo dijo a los Apóstoles, los primeros obispos: el que quiera ser más grande entre ustedes, hágase 
Por ello fueron Iglesias perseguidas (Mc 13, 9-13) por los poderes injustos de este mundo, como lo había sido Jesús ${ }^{18}$. Pues fueron Iglesias valientes que se pusieron al lado y del lado de los pobres, denunciando a los ídolos de este mundo, los poderes injustos, que amenazan al pobre (Ap 13; Rom 1, 18-32). Y nunca perdieron la esperanza ${ }^{19}$.

Y fueron también Iglesias profundamente ricas y plurales, de modo que a ellas se aplicará bien la imagen de Pablo que habla de la Iglesia como del Cuerpo de Cristo, en el que, formando una íntima unidad, la pluralidad de dones y servicios es lo que las distinguía $\left(c f r .1\right.$ Cor 12-14) ${ }^{20}$.

Fueron, finalmente, Iglesias dialogantes y respetuosas de la pluralidad de formas que fueron adquiriendo las Iglesias a medida que se fueron encarnando en los diversos lugares y culturas ( $c f r$. Ga 2, 1-10; Hch 15). Y, a la vez, apasio-

el más chiquito, sea el servidor de todos. Nuestro mandato es servicio; nuestra conducción, nuestra palabra es servicio" (Homilía del 23 de abril de 1978).

18. También en este aspecto, la Iglesia liderada por monseñor Romero fue afín al Evangelio: "Y me da más alegría todavía, cuando el Evangelio termina diciendo: 'Hasta vuestros padres y parientes y hermanos y amigos os traicionarán, y matarán a algunos de vosotros, y todos os odiarán por causa de mi nombre'. Hermanos, ¿quieren saber si su cristianismo es auténtico? Aquí está la piedra de toque: ¿con quiénes están bien?, ¿quiénes te critican?, ¿quiénes no te admiten?, ¿quiénes te halagan? Conoce allí que Cristo dijo un día: 'No he venido a traer la paz, sino la división y habrá división hasta en la familia'. Porque unos quieren vivir más cómodamente según los principios del mundo, del poder y del dinero, y otros, en cambio, han comprendido el llamamiento de Cristo y tienen que rechazar todo lo que no puede ser justo en el mundo" (Homilía del 13 de noviembre de 1977).

19. También en esos rasgos se descubre la profunda sintonía que tuvo monseñor Romero con las Iglesias que nacieron de la Pascua. La esperanza resuena a menudo en sus sermones. Recordaré sólo un texto: “¿Qué hermoso es ser cristiano! De veras, es abrazar la palabra de Dios encarnada, hacer suya la fuerza de salvación, tener esperanza aun cuando todo parece perdido. Por eso, mi trabajo, hermanos, aquí en catedral y en mi ministerio episcopal, y mi mayor satisfacción y alegría es cuando escucho al pueblo, como lo he escuchado en esta semana en diversas manifestaciones, que dicen que les transmitimos esperanzas, despertamos su fe" (Homilía del 16 de julio de 1978).

20. También este aspecto lo supo valorar monseñor Romero. En su homilía del 30 de septiembre de 1979, dijo: "Por eso, queridos hermanos — y yo aquí ya bajando a la realidad de nuestra arquidiócesis-, quiero admirar y darle gracias al Señor porque en ustedes, pueblo de Dios, comunidades religiosas, comunidades eclesiales de base, gente humilde, campesinos, ¡cuántos dones del Espíritu! Si yo fuera celoso como los personajes del Evangelio y de la primera lectura, diría: ‘Prohíbasele, que no hable, que no diga nada, sólo yo, obispo, puedo hablar!'. Y no, yo tengo que escuchar qué dice el Espíritu por medio de su pueblo y, entonces, sí, recibir del pueblo y analizarlo, y, junto con el pueblo, hacerlo construcción de la Iglesia!". 
nadas por la unidad entre todas ellas, sin menoscabo de su pluralidad ( $c f r$. Jn 17, 20-23; 1 Cor $1,10-13)^{21}$.

Esto es lo que comprendió muy bien monseñor Romero, de quien estamos celebrando el trigésimo aniversario de su martirio. Por eso su servicio eclesial estuvo marcado por la fidelidad a Jesús de Nazaret y a las Iglesias que nacen de la Pascua, unas Iglesias que han quedado atestiguadas en el Nuevo Testamento. Su recuerdo sigue vivo entre nosotros y en el mundo entero. Pues tal como él mismo anunció, ha resucitado en el pueblo salvadoreño. Y forma parte, como anuncia el Apocalipsis, de una muchedumbre enorme que nadie puede contar. Son gentes de toda nación, raza, pueblo y lengua, que están de pie, resucitados, delante del trono y del Cordero. Visten de blanco, llevan palmas en las manos y claman con voz potente: "A nuestro Dios, que está sentado en el trono, y al Cordero, se debe la salvación" (cfr. Ap 7, 9-10).

Pongamos, pues, a producir, la memoria de San Romero de América, como bellamente dijo monseñor Pedro Casaldáliga, para que así podamos seguir más fielmente a Jesús, tal como lo hizo monseñor Romero.

21. Son muchísimos los textos de Romero en los que él subraya su comunión con el Papa y con la Iglesia universal. 